\title{
Koera keele otsas rohi, kassi keele otsas tõbi
}

\author{
Renata Sõukand
}

\begin{abstract}
Teesid
Pealkirjaks olev vanasõna (EV 3352) esineb Eesti Kirjandusmuuseumi vanasõnade andmebaasis erinevates variatsioonides kokku 160 korral, mis on kassi kohta käivate vanasõnade seas esinemissageduselt teisel ja koera kohta käivate seas neljandal kohal. Artiklis selgitatakse selle uskumuse juuri ja tausta, vaadeldes mõlema looma käitumist ja harjumusi kooseksistentsis inimesega. Selline eristus kassi ja koera vahel on pigem inimese harjumuspärase tegevuse ja looma käitumisest tuletatud ootuste peegeldus, sest mõlema looma suus esinevad nii patogeensed mikroorganismid kui ka ravivad ained.
\end{abstract}

Märksõnad: harjumus, kass, koer, käitumine, lakkumine, ravi, sümbol

Kui end lapsena kriimustasin, käisin alati esimese asjana sellest ise keelega üle ja siis andsin oma koerale "põhjalikumaks desinfitseerimiseks". Mäletamist mööda paranesid need kriimud (mõnikord ka tõsisemad haavad) lausa imeväel. Kui aga kass - keda nii mõnus silitada oli, kui ta põlvel nurru lõi - katkist kohta lakkuma kippus, tõmbusin ise vaistlikult eemale või ajasin ta minema. Emapiimaga sisse imetud rahvatarkus koera keelel seitse rohtu, kassi keelel seitse ohtu avaldas mõju, lubamata isegi katsetada kassi keele tervendavaid omadusi.

Arstid ja ka veterinaarid väidavad nagu ühest suust (vähemalt ametlikult), et igasuguse looma haava manu laskmine on kohutav hügieeninõuete rikkumine ja selline katsetus või lõppeda tõsise infektsiooniga või vähemalt pikendada paranemist. Teatud olukordades on hoiatus igati õigustatud, kuid ometi on isegi platseeboefekt sedavõrd hea rohi, et ka tänapäeva meditsiin on tunnistanud selle igati toimivaks.

See uskumus ei olnud vaid minu pere siseasi. Eesti Kirjandusmuuseumi vanasõnade andmebaasis esineb vanasõna koera keele otsas rohi, kassi keele otsas tõbi (EV 3352) 160 korral, mis on kassi kohta esinemissageduselt teine ja koera kohta neljas vanasõna (Hus- 


\section{Renata Sõukand}

sar \& Krikmann \& Mikk et al. 1997). Ka Jakob Hurda rahvaluulekogu meditsiinitekstide seas esineb seda ütlust lõpututes variatsioonides, olgu näiteks toodud vaid mõned:

Kui pahad paised ehk haavad ihu peal on, lase koer lakkub seda. Paised ehk haava peab varsti ära paranema, sest koera suust saab rohtu ja abi. Aga kassi suust kihvti (H I 1, 378 (10) $<$ Risti khk - Juhan Holts (1889)).

Vanarahvas ütleb, et koera keele otsas olla üheksamat jagu rohtu, kassi keele otsas aga üheksat jagu tõbesid. Sellepärast ei ole see sugugi hea, kui kass lapse leiba-lapse käest-lakub (H I 9, 56 (54) < Setumaa - Anton Suurkask (1897)).

Usutse, et koera keele pääl ühesat seltsi rohi oleved, ja lastas sellepärast koeri iki kiksugusid haave lakku. Kassi keele pääl arvatse aga ühesat seltsi tõbe oleved ja hoidas sellepärast söögiraami kangeste kasse iest. Esiäranis arvatse kurguhaigust sellest tuleved, et kassist lakut sü̈ki oleved sööd (H II 42, 461 (79) < Halliste khk - H. Sulsenberg (1893)).

Kus on selle uskumuse juured? Kas sellel on ainult mütoloogiline ja usundiline taust, või leiab põhjendusi ka loomade otsestes käitumismallides? Antud kirjutis seabki endale eesmärgiks leida sellised kassi ja koera käitumuslikud jooned, mis inimese poolt tõlgendatult annavad põhjust teha vahet nende loomade "ravivõimetel".

\section{Kassid-koerad inimese majapidamises ja suhtumine neisse}

Kodukass (Felis catus) kuulub imetajate (Mammalia) klassi kiskjaliste ehk lihasööjate (Carnivora) seltsi kaslaste (Felidae) sugukonna kassi (Felis) perekonda. Tema eellaseks peetakse Aafrika metsikut ookerkassi (Felis libyca), kes arvatavasti kodustati Niiluse ürgorus 4000-5000, mõnede arvamuste kohaselt ka 9000 aastat tagasi (Akimuškin 1993; Alaots 1996; Brem 1996). Loomade kodustamise ajaloo käsitluses liigitab Juliet Clutton-Brock (1987) kassi kütkes rakendatavate loomade (exploited captives) hulka, koer aga kuulub inimkujundatud loomade (man-made animals) jaotusse. 


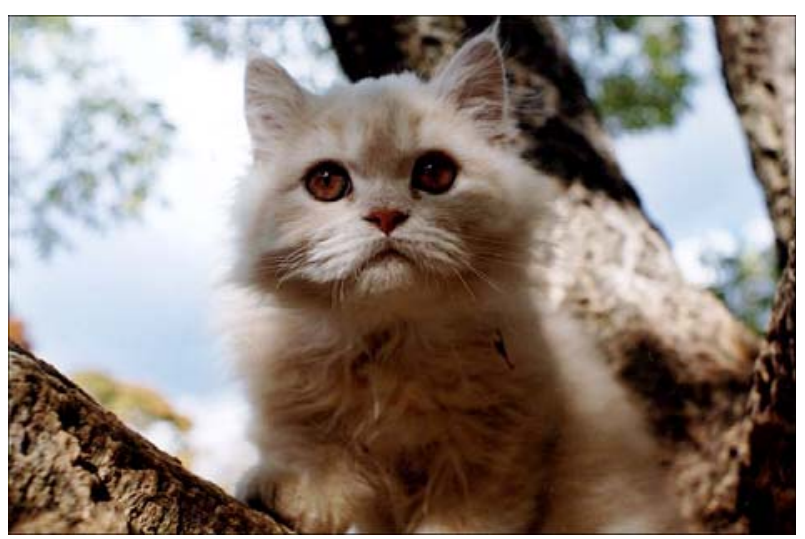

Foto 1. Kass teeb mis teeb, aga mõnikord võib pererahva meeleheaks poseerida ka. Renata Sõukandi foto.

Raske on öelda, kelle initsiatiivil kass kodustus. Kas põllupidaja avastas kassi kasulikkuse ületalve hoitavat saaki ohustavate näriliste hävitamisel või leidis hoopis kass, et tal on inimese juures turvalisem ja lihtsam hakkama saada - tõestusi leiab mõlema oletuse kinnituseks. Iseseisva iseloomuga kass ei oleks lasknud end sunniviisiliselt kodustada ja ega inimenegi aastatuhandeid tagasi lisasuud peresse üksnes silmailuks ja hellitamiseks oleks võtnud.

Muinas-Egiptuses oli kass püha loom. Teda peeti viljakus-, jahija ööjumalanna sümboliks. Kassi tapmise eest karistati surmanuhtlusega, tema surnukeha maeti palsameerituna kirstus ja tulekahju korral päästeti majast kõigepealt kass. Aastal $535 \mathrm{eKr}$ kaotasid egiptlased kassi jumaldamise tõttu isegi sõja pärslaste vastu, kelle sõjakavalus seisnes selles, et igal rünnakule mineval sõdalasel oli süles kass, ja Egiptuse amburid, kartes tabada kasse, ei lasknud välja ühtegi noolt (Alaots 1996).

Vahemeremaadesse sattusid kassid importloomadena vaatamata rangetele väljaviimiskeeldudele. Sealt levisid nad hiljem Indiasse, Hiinasse ja ka Euroopasse. Vanas Roomas oli kass vabadusjumalanna sümbol ja et ta kaitses kodusid, oli ta ka koduhoiu sümbol.

Varakristlikus kultuuris suhtuti kassisse sallivalt. Näiteks oli kass ainus koduloom, keda lubati pidada nunnakloostrites. Kuid hiljem kuulutati loom põrgu sigidikuks, kusjuures sallimatus jõu- 


\section{Renata Sõukand}

dis nii kaugele, et katoliiklikus Euroopas praeti vaeseid kasse suure paastu ajal elusalt kas puurides või vardas. Neid jälitati ja piinati, hukati kui saatana käsilasi, eriti kehtis see mustade kasside kohta. Samuti oli keskajal Euroopas suur nõudlus kassielunditest valmistatud rohtude järele (Akimuškin 1993; Alaots 1996).

Kassi demoniseerimine ei ole omane vaid kristlikule kultuurile. Mongoolia šamaanid laulavad: Kassi keel on pleekinud ja koera karv määrdunud. Sellega meenutatakse vana lugu, et jumal lõi savist esimese mehe ja naise ning jättis kassi ja koera neid valvama, kuni ta ise läks tooma igavese elu vett surematuse allikast. Kuid kurat ostis valvurid ära, pakkudes neile piima ja liha, ning urineeris jumala loomingu peale. Jumal läks marru, kui nägi oma kätetööd katvat karvastikku selliselt rüvetatuna, ja käskis kassil karva maha lakkuda (välja arvatud pea pealt). Kass lakkus maha kõik kästu, nii kuis kätte sai, peale kubeme ja kaenlaaluse piirkonna. Kareda kassikeelega maha lakutud karva pani jumal nüüd koera selga. Seejärel kastis jumal inimesi eluveega, kuid ei suutnud siiski inimest surematuks teha just kuradi eestvõttel aset leidnud rüvetamise pärast (Cotterell \& Auerbach 2002: 176).

Islamiriikides peeti kasse jumaliku olevusena au sees, sest prohvet Muhamed olla kasse väga armastanud. Legend räägib, et kui üks neist magas tema varrukal, lasi prohvet, et mitte oma lemmikut häirida, varruka ära lõigata, kui ta ise pidi kohalt lahkuma (Akimuškin 1993).

Renessansiajal taastati kassi eluõigus ka Euroopas ja jätkuvalt kasutati neid peamiselt näriliste looduslike hävitajatena. Üks täiskasvanud kass suudab päevas hävitada kuni 20 hiirt, vajadusel ka putukaid ja madusid (Brem 1996: 187). Esines ka kassikasvandusi, kus neid loomi peeti karusnaha saamiseks - näiteks 19. sajandi lõpul Hollandis, Belgias ja Saksamaal (Brem 1996: 188). Kassiliha on kasutatud ka toiduks, eriti näljaaegadel. Nt Alfred Edmund Bremi (1996) raamatus Loomade elu on tsitaat, milles pannakse Étienne de Geoffroy Saint-Hilaire' ${ }^{1}{ }^{1}$ suhu ühe lõunasöögi kirjeldus vaenlasest piiratud Pariisis:

Kassifilee oli suurepärane. See valge liha on hea vaadata, pehme hammustada ja meenutab jahutatud noorlooma liha (Brem 1996: 188).

Praeguses heaoluühiskonnas on kass tihti "padjaloom", koduhoidja ja stressimaandaja, kuid põhitöö on neil ikka sama: nt Sankt-Peter- 


\section{Renata Sõukand}

burgi Ermitaažis on tööl terve "brigaad" kasse, kes hiiri keldrikorruselt kaugemale ei lase.

Koerad kuuluvad kassidega samasse karnivooride seltsi, kuid koerlaste (Canidae) sugukonda. Kodukoer (Canis familiaris) pärineb ilmselt hundist, šaakalist või mõnest teisest neile lähedasest kiskja ning kodustati juba kiviajal (Bannikov \& Flint \& Gladkova 1987). Siiski on täpset daatumit raske paika panna: koerte koljusid, mis kindlalt viitavad kodustamisele, on leitud ajast, mil Euroopas leidus veel mammuteid. Kindlalt võib väita, et koer oli esimene kodustatud loom. Koer oli nii kaitsjaks kui ka abiliseks, ohu eest hoiatajaks ja "bioloogiliseks radiaatoriks" jaheda ilma korral. Arvatavasti just tänu koerale sai inimene liikuda edasi külmematele põhjaaladele ja kodustada teisi paremaks hakkamasaamiseks vajalikke loomi (Brem 1996).

Paljudes kultuurides suhtuti koertesse suure austusega. Nagu kassid, nii olid ka koerad Egiptuses aukohal. Neid seostati jumal Setiga ja kasutati jahil. Koera tapmise eest karistati surmanuhtlusega. Kreeklased seostasid koeri eskulaapidega ja keldidki uskusid, et koeral on ravivõimed. Egiptlased ja kreeklased uskusid, et truu koer järgneb oma peremehele ka surmajärgsesse ellu. Paljudes kultuurides usuti, et koerad on vahendajateks elusate ja surnute vahel. Mitmed Aafrika hõimud peavad koera tsivilisatsiooni esiisaks ja tuletoojaks.

Koerad on truuduse ja kiindumuse sümboliks, samas ka roojasuse ja kõlvatuse märgiks. Euroopa pärimustes on lambakari riigi metafooriks, karjane tähistab valitsejat ja lambad kuulekaid kodanikke, koerad aga on valitseja truud alamad. Karjane ei saa hakkama ilma koerata, kuid kohtleb teda siiski austuseta. Kui koer sattus kristlikku pühamusse, ootas teda halastamatu peks või koguni surm, kusjuures pühamu tuli seejärel uuesti pühitseda. Samas viitab dominikaanide ordu nimetus (domini canes 'jumala koerad') koera truudusele kui ülimale ustavusele. Loomapsühholoogi ja zoosemiootik Aleksei Turovski (2004) ütleb: kui jumal ravib hingehaavad, siis koer ravib kehahaavad. Eriti roojaseks peeti koera semiidi ja hindu traditsioonis. Islami maailmas peetakse musta koera saatana sümboliks.

Tänapäeval on koer asendamatu kodu- ja muu territooriumi valvur, jälitus- ja narkotöötaja, rakendivedaja, lapsehoidja, küljesoojendaja, lisaks muud kõikmõeldavad ametid. Hiinas süüakse koeri tänini ja nii mitmeski kohas kasvatatakse koeri karusloomana. Igaüks kasutab truud abilist nii kuis oskab. 


\section{Renata Sõukand}

Kassi ja koera staatus, vaatamata teatud ajaloolistele ja iseloomuomadustest tulenevatele eripäradele, on üsna võrdväärne mõlemat looma on vahelduva eduga peetud pühaks ja roojaseks, mõlemat on kasutatud inimese hüvanguks ja koheldud kord õiglaselt, kord ebaõiglaselt. Seega ei anna rahvusvahelise materjali mütoloogilise ja usundilise tausta võrdlus piisavat põhjendust eristamaks põhjalikult koera ja kassi keele raviomadusi.

\section{Kass ja koer eesti rahvapärimuses}

Mõlemad koduloomad on olnud eestlaste elus tähtsal kohal. Eesti vanasõnades kajastub suhtumine loomadesse mitmekülgselt, kuid siiski üsna üheselt mõistetava eristusega. Lisaks juba mainitud "ravivõimete" eristusele tehakse vahet mitmetes teisteski valdkondades. Koera elu peeti raskeks (külmas ja näljas, pidevalt haukuv ja valvel) ning vastandati kassi sooja ahju varjus piimakausi kõrval istumisele. Väljendid koeraelu 'vilets, raske elu', koeraamet 'tänamatu amet v töö', koerapõli 'vilets, raske elu' ja koerailm 'kehv, hrl sajune ilm' (ÕS 1999: 306) ei viita just ihaldusväärsele ametile ja seega mööndi sel-

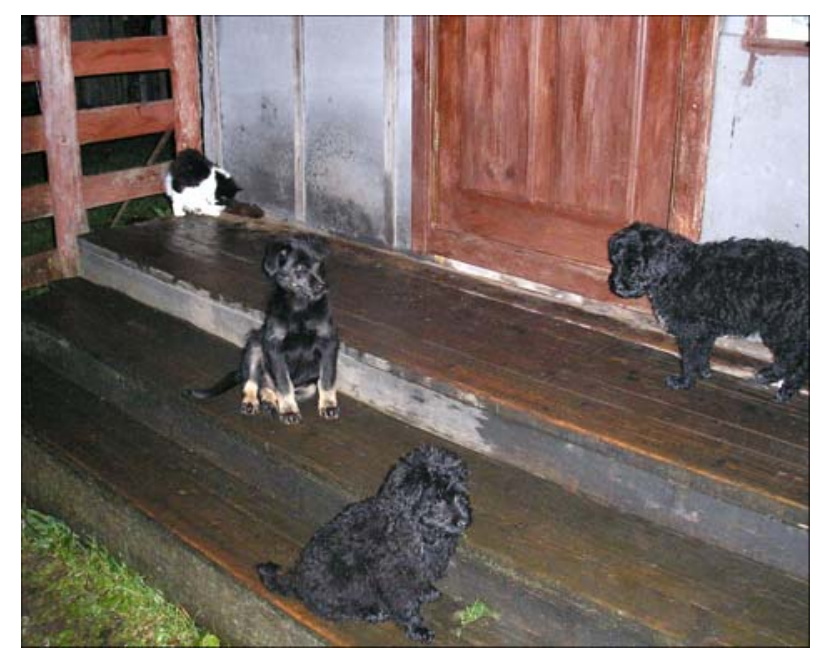

Foto 2. Parem karta kui kahetseda - kutsikate mänguhimu tundev vana kass hoiab heaga omaette. Raivo Kalle foto. 
le alandlikku talumist. Ka eesti vanasõnad (Hussar \& Krikmann \& Mikk et al. 1997) iseloomustavad koera ja kassi erinevalt. Koer saab kirikuski peksa (EV 102) ja koera palk on malk (EV 4075), kuid küll koer oma haavad parandab (EV 4145). Kassi seevastu peeti pirtsakaks, kes kunagi millegagi rahul ei ole ja ikka metsa poole vaatab: kass sööb oma saaki alati nurisedes (EV 3383) või kiida kassi, kass läheb pahuraks (EV 3728). Ka ei saanud kassi peale kunagi kindel olla: mõisa au, kassi näu-ühesugused (EV 6986), isane kass ja vanapoiss muudavad sagele oma meelt (EV 2225) ja kass sööb selle kasu ära, mis külas kasvab (EV 3384).

Arvestades arvamust kassi keele mürgisuse kohta, võib vanasõna kas kass katsund või lakkund, on ükskõik (EV 3348) pidada hoiatuseks kassiga liiga tiheda läbikäimise eest.

Eesti Rahvaluule Arhiivi kogude põhjal on näha samasugust tendentsi. Koer seondub eelkõige peremehega, kass aga koduga. On täheldatud nii kasside kui ka koerte tundlikkust igasuguste (eeskätt negatiivsete) muutuste suhtes ja neile on omistatud teatud ennustajavõimeid. Eeskätt musta kassi üle tee jooksmine tähendab enamjaolt pigem õnnetust kui õnne.

Palju on teateid kasside kui ilmaennustajate kohta.

Kui kass end vastu päeva peseb, tuleb kõva vihmasadu (RKM II 41, 390 (63) < Pöide khk, Orissaare v - M. Liin (1954)).

Kui kass kakub kü̈̈stega, tuleb tuult ja tuisku (RKM II 92, 20 $(1,125)<$ Kambja khk - A. Kelli (1958)).

Kui kass pliidi või ahju otsa tükib talvel magama, siis minevad ilmad külmale (RKM II 35, 277 (2) > Tõrva khk - Endel Maasik (1948)).

Kui kass oksendab ja rohtu sööb, tuleb kurja ilma, vihma ja tuult ja tormi. See küll õige (ERA II 191, 481 (98) < Muhu khk - Marta Viidalepp (1938)).

Samas on ilmaennustamise võime omistatud samaväärselt ka koerale, kuigi selle kohta on Eesti Rahvaluule Arhiivis veidi vähemal hulgal väiksemate variatsioonidega tekste.

Kui kass ja koer heina söövad, läheb ilm pahaks (RKM II 334, 247 (35) < Hargla khk, Mõniste v, Mõniste k - Kadri Jaagupalu (1978)). 


\section{Renata Sõukand}

Kui koer süüa ei taha, on nagu haige, tuleb sadu (RKM II 42, 422 (2) < Märjamaa khk - Emilie Poom (1955)).

Ka aimavat kassid ette külalise tulekut, kusjuures sõltuvalt kassi käitumisest võis ennustada, kas tulemas on mees- või naissoost külaline, hea või halb jne.

Peseb kass silmi, siis tuleb külalisi (RKM II 283, 435 (68) < Viru-Jaagupi khk - Hugo Lepiku (1971)).

Koerad on tundlikud igasuguste muude halbade asjade suhtes, olgu selleks surm, ikaldus või tulekahju, hoiatades sellest omal moel ka peremeest.

Kui koerad õue peal haukusid, kraapisid, tuleb sel aastal surm (H II 40, 906 (38) < Risti khk).

Kui koer leivatüki maha matab, tuleb ikalduseaasta, koer tunneb seda ette ja paneb omale leiva tagavaraks (E $78549(19)<$ Otepää khk - A. Mirs).

Koer tunneb tulekahju ette. Kui tuleb majas tulekahju, koer ei tule majja, kui kutsutigi õhtul sööma, ei tulnud (ERA II 138, 560 (19) < Tartu l - Aleksandra Grünvald-Univer (= Aili Univere) (1937)).

Koerale omistati ka võime mõista peremehe tujusid ja tahtmisi.

Kui teise pere koer teise peresse läheb sitale või kusele, siis on see pere vihane teise peale (ERA II 164, 220 (68) < Kihelkonna khk - Linda Köögardal (1937)).

Ka tervisega seonduvates küsimustest saab Eesti Rahvaluule Arhiivi materjali põhjal arvestatava ülevaate. Kass, õigemini temaga kokku puutunud toit, asi vms, võis põhjustada mitmesuguseid haigusi.

Kes kassi lakutud riista seest kõige enne sööb, see jäeb nahahaigusesse (H II 43, 542 (11) < Kolga-Jaani khk - K. F. (1893)).

Kassi karvu ei tohtide suhu aada, siis minne hääl ära (H II 47, 498 (4) < Tõstamaa khk - Otto Schantz (1894)).

Koera puudutatud toit oli aga ohutu, pigem võis kindel olla, et see kõlbab süüa. 
Kost pini um laknu, säält võit iks süvvä, tuo peräst olõ õi midägi, a kost kass um söönü, hott ku võrrakõisi, säält sünnu ui süvvä. Pini keele otsah um ütsä tõbõrohi, a kassi keele otsah um ütesä tõpõ (H II 3, 561 (1) < Vastseliina khk - Hindrik Prants (1888))

Kassi kaudse abiga raviti haigusi, mis olid kassist enesest põhjustatud: köha, nohu, kurguvalu. Kusjuures siingi on oluline koht just kassi keele (või ka karvastiku) kahjulikkusel.

Ku sedä leibä süöd, mis kass om ärä närinu, sõs jääb kurk haigesse ja üteldas: kassikaru om kurku minnu. Võta sõs kass kinni, silitsa kassi hännä ja käpäga kurku, sõs saab kurk tervesse (H II 25, 409 (7) < Tarvastu khk - Aadu Rull (1890)).

Kui sõuke kerge köha oli, see kutsuti kassiköhaks ning see tuli sellest, et oli säältkuhast vett joodud, kust kaiss oli lakkunud. Pidi kassile kurku puhuma, siis kadus köha ära (RKM II 35, 58 (97) < Kihelkonna khk - Priidu Võtti (1950)).

Sulu ehk kassitõbe, kus nina kiheleb ja kinni on, vett jookseb ja turtsuma aiab, piab mõnikõrd kassisabaga nina õeruma ja pühkima (H II 26, 894 (28) < Pilistvere khk - H. Lindberg (1889)).

Kassi abi on kasutatud kaudselt teistegi haiguse ravimiseks, nagu joomarlus või kõhulahtisus.

Joodikule mehele antagu süsimusta kassi piima juua, ilma et joodik isi sellest midagi teab, siis peab ta joomise maha jätma ega kunagi enam viina- ega ôlletilka suhu võtma (H II 29, 303 (4) < Tartu - Voldemar Pärtelpoeg (1889)).

Kui lapsel kõht lahti on, antakse talle musta kassi karvadest põletatud tuhka, jälle aitavat (H II 74, 497 (40) < Palamuse khk - Hans Karu (1905)).

Mõned kiidavad roosi vastu hea abi olevat: musta lambanahkse kasuka küllest villu niita, kassi asja võtta, üheskoos tuhaks põletada ja peale panna, peab haigusele hea abi olema (H IV 8, 666 (38) < Palamuse khk, Kuremaa v - Hans Karu (1897)). 


\section{Renata Sõukand}

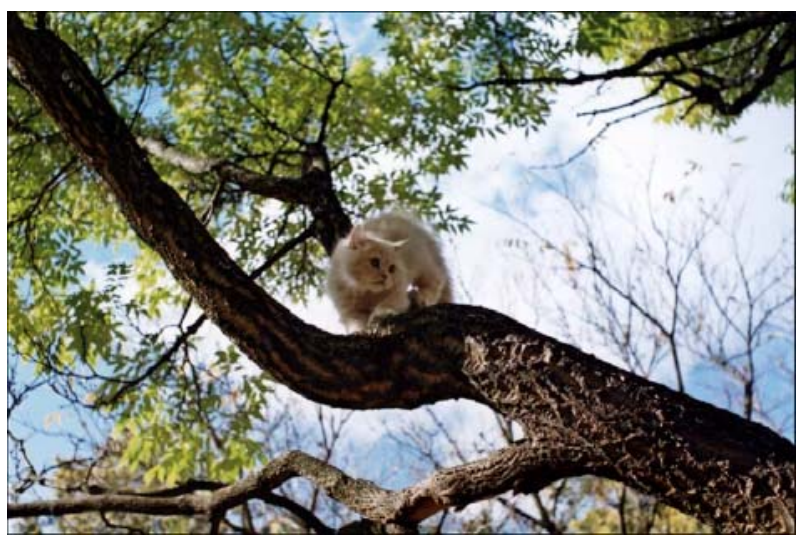

Foto 3. Kassi allumatus ja isepäisus on piiritu. Mis sest, et armas ja kodustatud diivanikiisu - kui tahab puu otsa, siis sinna ka läheb. Renata Sõukandi foto.

Ka koera ekskremente, karvu jms on kasutatud kaudseks raviks.

Kui sündind lapsel midagi veikest viga oli, nimelt nutmist, ringutamist, rüngimist jm, siis suitsetati enne ristimist koera-, sea-või mõne muu karvadega (H I 5, 212 (55) < Kaarma khk < Pöide khk - Thomas Undritz (1894)).

Sammaspoolt arstitakse: kui nähakse, kus must koer kuseb, siis võetakse seda kust ja määritakse haiged kohta, siis kaub ta ära (H I 7, 599 (7) < Palamuse khk - Martin Kitznik (1895)).

Kassile võis haiguse ka loitsuga edasi saata.

Kui laps haiget saab (jalg või käsi jne), siis puhutakse selle koha peale, pitsitakse ja muutsutakse nende sõnadega:

"Harakalle haigust,

vareselle valu,

musta linnul mu tõbi,

põdra põlve, karu käppa,

kassi jalga,

tõbi tulgu, teene mingu,

ärgu vaksa vahet olgu!

Meie lapse jalg (käsi) terveks!

Terveks, terveks, terveks!" 
Kui laps seda kuuleb, jäeb kohe vait (H II 26, 372 (10) < SuureJaani khk - Tõnis Köstner (1889)).

Samale ülekandmispõhimõttele vastavalt toimis uue asja kasutamine esmalt kassi peal.

Uue pääharjaga pieab enne, pääle meistre käest toomise kassi pääd sugima, siis ei minna kellegil pää kärna (H II 25, 377/8 (9) < Tarvastu khk - Jaak Käger (1890)).

See meenutab mitmel pool levinud uskumust, et uude majja tuli kõigepealt viia kass, lasta tal esimene öö seal magada ja alles siis võisid inimesed sisse kolida. Usuti, et esimesena uude majja sisenev kass võtab vastu seda kohta tabava esimese surma; kohta, kuhu kass pikali heidab, peeti parimaks voodikohaks (Devjatkina 2002).

Rahvasuus olid tuntud ka nn kassi- ja koeratõbi. Mõlema haiguse puhul kasutatakse ravimist loomakarvade, -uriini ja/või -verega, kassihaiguse puhul siiski ka kassiluuga.

Kassitõbi om harv küläline, kedä siiski mitme latse põdeva, kellel imä nii hull om olnu, et ta kassiga üteh maka. Tõbe tundemärk: lats maka niigu kass, kes ütteluku närises ja nurises. Arstmine: kolmõl vanakuu neläpäävä õdagul piät last kassikarvuga sautama, ehk kui tuo ei avitda, sis piät ütesä sä̈̈nest põllu-vai lubjakivvi korjama, koh kõõsugutsõ tsirguja eläjäjäle pääl omma. Nuo kivi piät tuliverevas ajasma ja sinnä kassi kust pääle valama ja sääl pääl last tossutamasaavat abi. Kellele kassitõbi mano om jätetü, tuol nakkas elo elleh alatõ kassikarv kurku. (Kass om kuri elläi, kassi keele otsah om tõbi) (H II 70, 530/1 (6) < Setumaa - Jaan Sandra (1904)).

Kui laps liiga kiunub ja kätega rabistab, siis olla lapsel kassiviga. See viga tulla lapsele sellest, kui kandja ema on palju kassi näumist ehk karjumist kuulnud ehk kassist kandmise ajal hirmutatud saanud. Seda viga parandati sellega, et lapsele kassi verd anti ehk kassiluudega last suitsetati (H II 20, 740/1 (11) < Vändra khk - J. Erm (1890)).

Kui veike laps väga ahmitseb ja pü̈̈ab suuga igalt poolt võtta, siis üteldi lapsel koeraviga olema. Koeraviga saada laps sellest, kui ema kandmise ajal koera söömise ajal ehk raasu- 


\section{Renata Sõukand}

keste otsimise ajal pealt vaadata. Seda viga parandasivad vanad inimesed sellega, kas last suitsetadi koerakarvadega ehk lasti koera kõrvast kolm tilka verd ja anti seda lapsele sisse (H II 20, 740 (9) < Vändra khk - J. Erm (1890)).

Analoogiliselt raviti ka kassi- ja koerahammustusi, kuigi loomulikult esines koerahammustusi rohkem ja seega on nende kohta ka rohkem teateid.

Saab inimene koerast ehk kassist hammustatud ja haav, kes küll suur ei pruugi olla, ometi valu teeb ja paistetama hakkab, paranevat kergesti, kui sellesama loomakarvu selja pealt südame kohalt leigatavat ja nende haiget kohta suitsetavat (H II 49, 397 (12) < Viljandi khk - Kreeta Karu (1894)).

Kui aga hammustust õigel ajal ja viisil ei ravitud, tekkis haava sisse koeraviha (kassikriimustuse korral kassiviha).

Koeraviha 'koera hammustamisel tekkiv paistetus on koeraviha tagajärg'; koeraviha - sii on hirmus, millal sii äe paraneb, küll sii aega vötab (KKI, KS < Kaarma khk - Aadu Toomessalu (1948)).

Koeralt haiguse saamise juures oli inimene ikka aktiivsem pool tavaliselt pidi ta midagi halba korda saatma: koera narrima, peksma vms. Mõnikord piisas ka millegi tegemata jätmisest, aga sellekohaseid teateid esineb harva.

Koera ei tohi jalaga lööja ega tõugata, sellest sigineda lööja või tõukaja naha peale koeranaelad (paised) (H I 10, 29 (20) < Risti khk - Johan(n) Reimann (1896)).

Kui sul paised on, siis määri need päält võiga ja lase neid mõnda koera lakuda, see annab head abi.

Koeranaelad ehk paised hakkavad selle läbi, kui koer ringutab. Et seda aga ära hoida, pead sa koerale kohe kolm korda silmi vahele sülitama, kui ta sinu poole juhtub ringutama. Ka selle läbi võivad sulle koeranaelad selga tulla, kui sa koera haugutad, s.o kui sa koerale leiba ehk midagi muud pakud, aga mitte temale seda kätte ei anna, vaid mitu korda teda nõndamoodi narrid. Koeranaelade kaotamiseks on ka veel see mõjus, kui sa võileivaga koeranaelu ehk paiseid vajutad ja siis selle võileiva koera kätte viskad ning koer teda ära sööb (H I 9, 384/5 (175) < Viljandi khk - Anton Suurkask (1897)). 


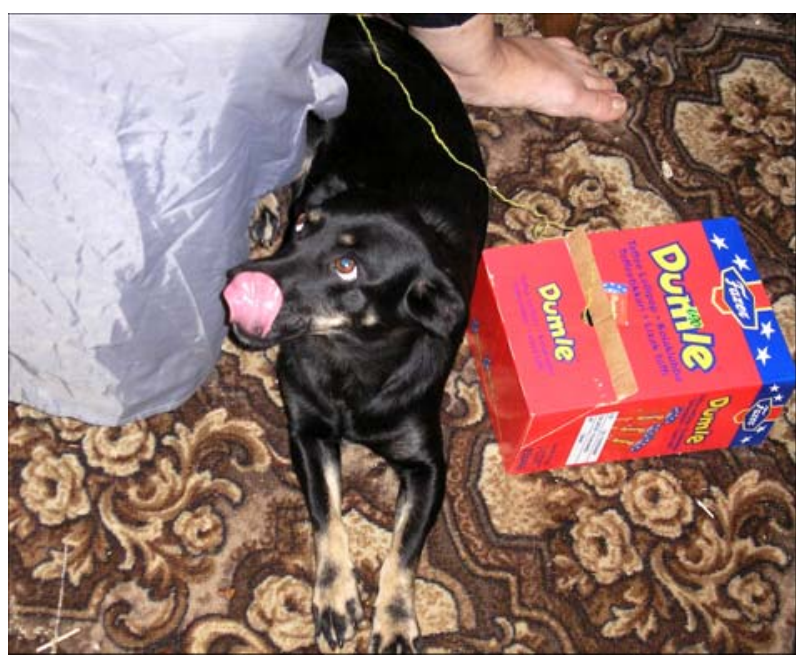

Foto 4. Sokke kuduva vanaema läheduses on mõnus mõelda muu seas ka millelegi suupärasele. Raivo Kalle foto.

Eeltoodud tekstist tuleb selgesti välja ka arstimisviis: haigus tuli koerale ära anda - ja see eeldas teadagi koerapoolset valmidust haigus endale võtta. Aktiivsed on mõlemad: nii leiba (tihti ilma igasuguse võita) pakkuv inimene kui ka seda vastuvõttev koer. Inimene eeldab, et tark loom peaks hästi teadma, mida talle pakutakse. Leiva ärasöömist võib vaadelda nagu lepitust ja samas nagu tänu hoidmise ja katmise eest. Nii raviti koera abil teisigi koeraga seotud haigusi.

Langetõbe arstida. Kui langetõbelisele tõbi peale tuleb ja haige suust vahtu välja ajab, siis peab nägija seda vahtu leiva peale panema ja koerale andma. Selle peale lahkub inimeselt tõbi ja läheb koera peale (H I 5, $116<$ Tallinn < Kolga-Jaani khk - Jakob Koit (1895)).

Sellist vabatahtlikku haiguste ülevõtmist kassi poolt pärimustekstid ei kajasta. Võib oletada, et kassi kui isepäist ja iseseisvat looma ei peetud valmiks osutama inimesele küsitud abi - sellisel juhul ei olnud ka selle üritamine vaeva väärt. Kusjuures väevõimuga teisele haiguse ülekandmine on juba teadja pärusmaa ja just vabatahtlikkuse moment, eeldatav aktiivne osasaamine inimese hädast ongi 


\section{Renata Sõukand}

koera keelele raviomaduste omistamise juures oluline. Sellepärast pakutaksegi koerale haava lakkuda, et usutakse teda teadlikult haigust ära võtvat, tahtes inimest kui sõpra terveks ravida, kassi aga arvatakse osavõtmatult lakkudes (juhul, kui ta selleks üldse nõustub) hoopis paranemise kulgu pikendavat.

Haiguse levitamise seisukohalt on need loomad rahvausundis olnud suhteliselt võrdväärses staatuses. Näiteks katkupärimusega seoses on esinenud teateid nii kassi kui ka koera kohta.

Lõuna-Eestis on katku mitmel korral kujutatud punase või musta koerana. Kassi ilmumisest on kakskümmend teadet, valdavalt on kass must, kirju või punane. Udmurtidelt ja komidelt on samuti andmeid raskeid nakkushaigusi toovate vaimude liikumisest koera või kassi kujul (Hiiemäe 1997: 59).

\section{Kassi ja koera käitumisnormid haavalakkumise kontekstis}

Seotuna kassi ja koera keele ravitoimega on ilmselgelt oluline vaatluse alla võtta kaks käitumisnormi, mis on selle teemaga otseselt seotud: sotsiaalne käitumine (ka inimesega suhtlemine) ja toitumisharjumused.

Kassi eellane on olnud omaette hoidja ja üksi jahti pidaja, samas kui hunt oli karjaloom. Sellest tulenevad ka tänapäevaste kasside ja koerte erinevused sotsiaalses käitumises. Koer on seltsiv, hoiab pererahvast, samas kui kass hoiab pigem kodu ja alles seejärel - kui üldse - pererahvast. Koertega võrreldes on kasse raskem õpetada käske täitma.

Küll on kassidel üksteise lakkumine omapäraseks õrnuse ja lugupidamise avalduseks. See on sotsiaalne tegevus, mis loomi omavahel seob. Paljud kassid väljendavad oma lugupidamist peremehe või perenaise vastu sel viisil, et tõmbavad kareda keelega neil paar korda üle käe või ka nina, kui neil lubatakse seda teha (Alaots 1996: 50-51).

Erinevalt inimmaailmast, kus ärritaja puhul otsene ja vahetu vastus viibib, sest vahepeal toimub mõtlemisprotsess, jääb loomade käitumises vahepealne lüli ära ja ärritajale reageeritakse vahetult, pikalt järele mõtlemata (Cassirer 1999: 46). Järelikult ei saa väita, et loom otsustab, kas aidata inimest või mitte. 


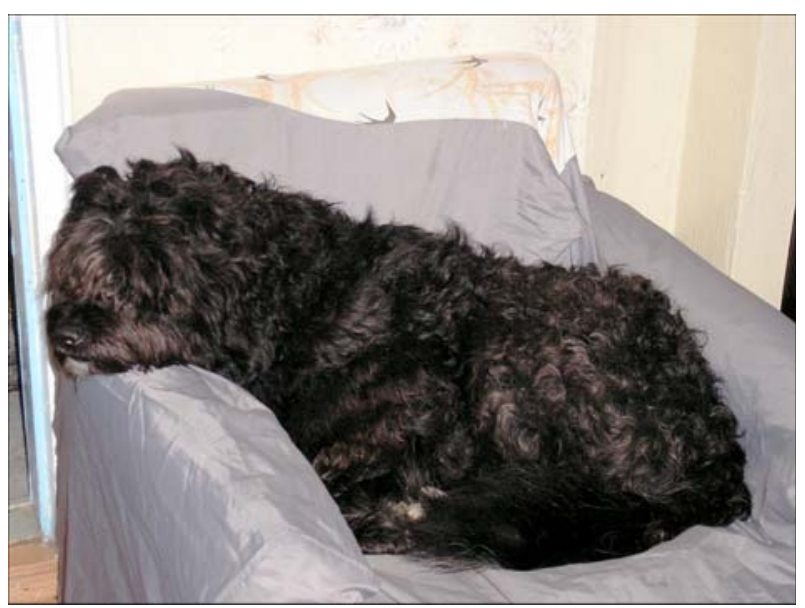

Foto 5. Koer armastab peremeest matkida. Raivo Kalle foto.

Muidugi ei saa välistada ega ka kinnitada, et koduloom käitub teatud situatsioonis kaalutletult. Charles Sanders Peirce'i järgi nõuab kaalutletud käitumine eelmiste, antud hetkega seotud kogemuste mäletamist ja tegevuse rakendamist iseenda hüvanguks (Peirce 1974: 5.538). Loom võib küll mäletada eelmist lakkumist, kuid vastuseta on küsimus, kas ta teeb seda kindlal eesmärgil. Siiski on kahe looma puhul märgata olulist erinevust reaktsioonikiiruses. Koer reageerib kohe impulsiivselt, tihtilugu tõmbab keelega ka niisama üle, ilma et teda oleks palutud. Kass seevastu, olles hiirejahi ja ka vaenlase eest põgenemise puhul valmis talitama silmapilkselt, reageerib kutsele aeglaselt, nagu mõtiskledes ega näita reeglina ise initsiatiivi üles. Kassi lakkuma kippumine tundub inimesele kahtlane, sest ei kuulu looma tavapäraste toimingute hulka, harjumuspärasesse miljöösse. Jääb mulje, et kassi arvates ei ole tegemist loomuliku, talle huvi pakkuva toiminguga, sest inimese positiivne reaktsioon ei ole kassile nii oluline kui koerale.

Mõlemad loomad on lihasööjad, nende eellased ja sugulased hangivad toidupoolist jahti pidades kas üksi (kass) või karjakaupa (koer). Ka inimese juures elades on neil kujunenud veidi erisugused toitumisharjumused. Kass toitus (19. sajandil) peamiselt jahisaagist, harva andis inimene talle midagi lisaks. Koer seevastu sai enami- 


\section{Renata Sõukand}

ku oma toidust pererahva käest. Või nagu ütleb eesti vanasõna: $k o e-$ ral peab olema oma korter ja talu söök, kassil aga talu korter ja oma söök (EV 4071).

Karjas elamist arvestades on toidu ablas neelamine täiesti normaalne ja kasulik söömisviis. Haarates suured tükid, tühjendab koer toidukausi mõne sekundiga ning vaatab siis nukralt inimesele otsa justkui lisa küsides. Koera silmis kujutavad inimesed endast oma karjakaaslasi - ta tunneb vajadust nendega võistelda, aga ka nende eest hoolitseda. Kiirele söömisele järgneb mõnikord oksendamine, kuid ka see on koerte, eriti emaste koerte puhul normaalne, sest viimased väljutavad toitu ka selleks, et toita oma kutsikaid (Fogle 1996: 85). Kass peab olema väga näljane, et ummisjalu toidu kallale söösta. Ta sööb rahulikult, vaatajale selga keerates, tihtilugu mõnust urisedes, mida eesti talupojad tõlgendasid tihti nurinana viletsa söögi üle.

Rohu söömisel ja selle väljaoksendamiselgi on väga ratsionaalne seletus: kassidel on normaalseks seedetegevuseks vajadus rohelise järele, mida nad meelsasti söövadki. Veel enam, rohu söömine on vajalik makku kogunenud karvapallide väljaoksendamise provotseerimiseks (Alaots 1996: 96). Koerad ei söö ükskõik millist rohtu, vaid otsivad söögiks teatud taimi ja umbrohtusid. Erinevalt kassidest on koerad võimelised ise tootma olulisi rasv- ja aminohappeid - nad suudaksid ellu jääda ka ainult taimetoitu saades (Fogle 1996: 83).

Kuigi klassikalisel juhul söövad hundid suuri rohusööjaid, nagu põder, sobivad neile toiduks ka paljud väikesed närilised. Kuid selle asemel, et istuda nagu kass kannatlikult uru juures ja oodata toidu välja ilmumist, kasutab hunt esikäppasid, et kaevata seal, kus näriline on maa alla pugenud, kuni ta oma saagi leiab. See on üks põhjusi, miks koerad kaevavad auke ja jätavad need siis maha. Ka hundid peidavad sageli üleliigset toitu. Koerad kaevavad ka lihtsalt igavusest või välja pääsemiseks, kuid ka selleks, et ergutada oma aistinguid. Maapind vabastab kaevamisel tohutu lõhnabuketi: vihmaussid, putukad, laguained, niiskus - kõik, mida koer naudib (Fogle 1996: 24).

Koeral on loomulik huvi väljaheidete vastu. Erinevalt kassidest, kes eelistavad süüa nii värsket toitu kui võimalik, söövad koerad meelsasti raibet. Kass sööb kaua hoietu, peni pikka peetu, ütleb eesti vanasõna (EV 3382). Maitseküsimused on koerale tähtsad, kuid 
mitte nii tähtsad kui inimesele. Toidu lõhn ja struktuur on tähtsamad kui maitse - väljaheited lõhnavad ja tunduvad suurepärastena. Sõnnik, eriti rohusööjate oma, on koertele toitev söök, mis sisaldab koera seedimisele vajalikke ensüüme ja toitaineid (Fogle 1996: 76).

Mõlema looma (nagu ka enamiku kodu- ja metsloomade) hingamisteedes, suus ja maos esineb grammnegatiivne bakter Pasturella Multocida, mis annab loomale ühe võimaluse saak vastupanuvõimetuks teha (Pappagianis 2004; Question and Answer with AWRE 1998).

Veel kaks, eriti käesoleva uurimise kontekstis, olulist detaili:

1) Terve koera suu ja keel ei põhjusta inimese haigestumist (Lindblom \& Oja 1995: 17), vaid vastupidi - koera süljes leidub ka mikroobe hävitavaid aineid (Essenson \& Joosepson \& Kadarik et al. 1985: 31). Kassi kohta aga üheski läbitöötatud raamatus sellist vihjet ei leidunud.

2) Kassi keel on kare, koera keel sile, pehme. Nahahaigusega kahjustatud piirkond ja ka värske haav on valu suhtes eriti tundlik. Valu, mida inimene tunneb kassi kareda keele puudutusest, võib tingida loomuliku reflektoorse vastuse - kass paisatakse haigest kohast eemale. Seegi tõik võib toetada uskumust, et kassi keelel on tõbi, ennetamaks teiste sootsiumikaaslaste edaspidist haigetsaamist.

\section{Lõpetuseks}

Eelnevast tulenevalt võib järeldada, et haava koerale lakkuda andmine kuulub pigem inimese harjumuspäraste tegevuste hulka. Iga harjumuse taga on meis toimiv uskumus, mis muutub kinnistunuks siis, kui konkreetset teadmist praktiliselt teostades saadakse kinnitust selle paikapidavusele. Seda kinnitust ammutas eestlane nii rahvausundist kui ka looma jälgimisel saadud kogemustest. Võib öelda, et vanasõna koera keele otsas rohi, kassi keele otsas tõbi (EV 3352) kujunemisel on olulist osa etendanud kõik eelvaadeldud faktorid ja see ei ole taandatav ühele kindlale looma käitumuslikule omadusele. 
Renata Sõukand

\section{Kommentaar}

${ }^{1}$ Étienne de Geoffroy Saint-Hilaire (1772-1844), prantsuse zooloog, natuurfilosoof, Prantsuse Teaduste Akadeemia liige (1807), Pariisi ülikooli professor (1793). Teda peetakse Darwini eelkäijaks, kes järeldas võrdlevast anatoomiast lähtudes, et loomaliigid muutuvad ja kõrgemad vormid arenevad madalamatest (toim).

\section{Kirjandus ja allikad}

\section{Arhiiviallikad}

$\mathrm{H}=$ Jakob Hurda rahvaluulekogu, 1860-1906.

E = Mattias Johann Eiseni rahvaluulekogu, 1880-1934.

ERA = Eesti Rahvaluule Arhiivi rahvaluulekogu, põhiliselt 1927-1944.

KKI, KS = Eesti Keele Instituudi Emakeele Seltsi murdekorrespondentide sõnavarakogu.

RKM = Eesti TA Fr. R. Kreutzwaldi nim (Riikliku) Kirjandusmuuseumi (nüüd Eesti Kirjandusmuuseumi) rahvaluule osakonna rahvaluulekogu 1945-1995.

\section{Kirjandus}

Akimuškin 1993 = Акимушкин, Игорь. Мир животных: Безпозвоночные, ископаемые животные. 2., täiend tr. Москва: Мысль.

Alaots, Jaagup 1996. Kassid: Lühike sissejuhatus kassiteadusesse. Tallinn: Valgus.

Bannikov, Andrei G. \& Flint, Vladimir J. \& Gladkova, Tatjana D. 1987. Imetajad. Loomade elu 7. Tallinn: Valgus.

Brem 1996 = Брем, Алфред Эдмунд. Жизнь животных 1: Млекопитающие. Москва: Терра.

Cassirer, Ernst 1999. Uurimus inimesest: Sissejuhatus inimkultuuri filosoofiasse. Tartu: Ilmamaa.

Clutton-Brock, Juliet 1987. The natural history of domesticated animals. Austin: University of Texas Press.

Cotterell, Arthur \& Auerbach, Loren (toim) 2002. The Encyclopedia of World mythology. Bath: Parragon. 


\section{Renata Sõukand}

Devjatkina, Tatjana 2002. Kodu (kud, kudo). Devjatkina, Tatjana. Mütoloogiasõnastik (http://www.folklore.ee/rl/folkte/sugri/mordva/myto/kodu.htm - 16. veebruar 2006).

Essenson, Albert \& Joosepson, E. \& Kadarik, Kaarel \& Kikkas, J. \& Pihlamäe, Uno \& Saks, Paul 1985. Koer. Tallinn: Valgus.

Fogle, Bruce 1996. 101 küsimust, mida sinu koer küsiks oma loomaarstilt (kui su koer oskaks rääkida). Tallinn: Sinisukk \& Co.

Hiiemäe, Reet 1997. Eesti katkupärimus. Monumenta Estoniae antiquae 2. Eesti muistendid: Mütoloogilise haigused 1. Tallinn: Eesti Keele Instituudi Folkloristika osakond \& Eesti Kirjandusmuuseumi Eesti Rahvaluule Arhiiv.

Hussar, Anne \& Krikmann, Arvo \& Mikk, Katrin \& Krikmann, Luule \& Vesik, Sander 1997. Vanasõnad (http://www.folklore.ee/rl/date/robotid/ leht1.html - 10. mai 2004).

Lindblom, Lasse \& Oja, Seppo 1995. Hoia oma koera: Koonust sabaotsani. Tallinn: Ilo.

Pappagianis, Demosthenes 2004. Gram negative rods. Yersinia, Brucella \& Francisella Lecture 16 (http://medocs.ucdavis.edu/mmi/480b/Syllabus04/ppt/yersinia-brucel-francis-16.ppt - 14. jaanuar 2005).

Peirce, Charles Sanders 1974. The Collected Papers of Charles Sanders Peirce 5:Pragmatism and pragmaticism \& 6: Scientific metaphysics. Hartshorne, Charles \& Weiss, Paul (toim). Cambridge (Massachusetts): The Belknap Press of Harvard University Press.

Question and Answer with AWRE 1998. 15. märts. All Wildlife Rescue and Education, Inc. (http://www.awre.org/Q\&A/Q\&A_3_15_98.htm - 14. jaanuar 2005).

Turovski, Aleksei 2004. Suuline teade Renata Sõukandile. 13. mai.

ÕS 1999 = Erelt, Tiiu \& Leemets, Tiina \& Mäearu, Sirje \& Raadik, Maire (koost). Eesti keele sõnaraamat. Tallinn: Eesti Keele Sihtasutus. 